\title{
EXAMINING THE VALUE OF EXPERT TESTIMONY REGARDING WARNINGS
}

\author{
Session Organizers and Co-Chairs: \\ Timothy P. Rhoades \\ Applied Safety and Ergonomics, Inc. \\ Ann Arbor, MI \\ J. Paul Frantz \\ Applied Safety and Ergonomics, Inc. \\ Ann Arbor, MI
}

\author{
Participants: \\ Donald P. Horst \\ Consultant \\ Sunnyvale, CA \\ Kenneth R. Laughery \\ Rice University \\ Houston, TX \\ Jerry L. Purswell \\ University of Oklahoma \\ Norman, OK
}

\begin{abstract}
This alternative format session is designed to examine the value of expert testimony related to warnings. Specific objectives of the session include informing HFES members of the views of some members of the legal community who question the value and appropriateness of expert testimony regarding warnings; identifying appropriate responses to such positions; discussing the basic role that experts play in assisting the litigation process; and describing and discussing the perceptions and experiences of HFES members regarding the value of their activities in forensic matters.

This session begins with a brief description of articles authored by an attorney, William Hardie, whose position is summarized by the following statement:

The defendant should try to exclude all opinion evidence on warnings, leaving the evaluation of the warnings to the jury and lawyer's arguments....The legal principles applicable to liability for failure to warn were developed by courts without the benefit of communication theorists. These legal principles are based on common sense, fairness, and the knowledge of ordinary people. In this spirit, juries are not well served by witnesses who are nothing more than professional advocates. (Hardie, 1991)
\end{abstract}

Session participants will respond to the above general proposition as well as other specific questions underlying Hardie's position and their own experiences as testifying experts. After participants answer directed questions, the format will allow for directed discussion between participants. Finally, the chair will attempt to articulate the common ground and differences between positions and solicit comments from the audience.

For those unable to attend the session but interested in the issue, below are articles authored by Hardie and referenced in this session:

Hardie, W.H. (August 10, 1990). The use of expert witnesses in product warning cases (Part 1). Product Safety \& Liability Reporter, Washington, D.C.: Bureau of National Affairs, Inc., pp. 895-902.

Hardie, W.H. (August 17, 1990). The use of expert witnesses in product warning cases (Part 2). Product Safety \& Liability Reporter, Washington, D.C.: Bureau of National Affairs, Inc., pp. 928-935.

Hardie, W.H. (October, 1991). Can experts evaluate the effectiveness of warnings? For the Defense, pp. 14-21. 